\title{
reviews
}

\section{Be a winner at the science Museum}

Have you ever fancied yourself as the next Sue Barker, Paula Radcliffe or Jonny Wilkinson? It's time to stop dreaming, says Naomi Davis.

The Science Museum is re-defining the concept of museum with its Science of Sport exhibition this summer.

The word 'interactive' has been taken to new levels at the exhibition, where visitors can dribble a football against the clock, climb an indoor rock face or race against each other in a sprint. You can even see an action replay. This is all achieved with the help of simulators and interactive displays.

The exhibition explores all things related to sport: coordination, ability, diet and exercise. You can learn about your own fitness by checking your pulse, measuring your height and weight and testing your reactions. And

for the less energetic there are displays about the inventions that have made sports people into record-breakers.

With the build up to the Olympics already started and Euro 2004 almost upon us, sport is going to be the next big thing this summer, so get ahead of the crowd and go see what the Science Museum is shouting about. You may even get to spend a moment in your hero's shoes.
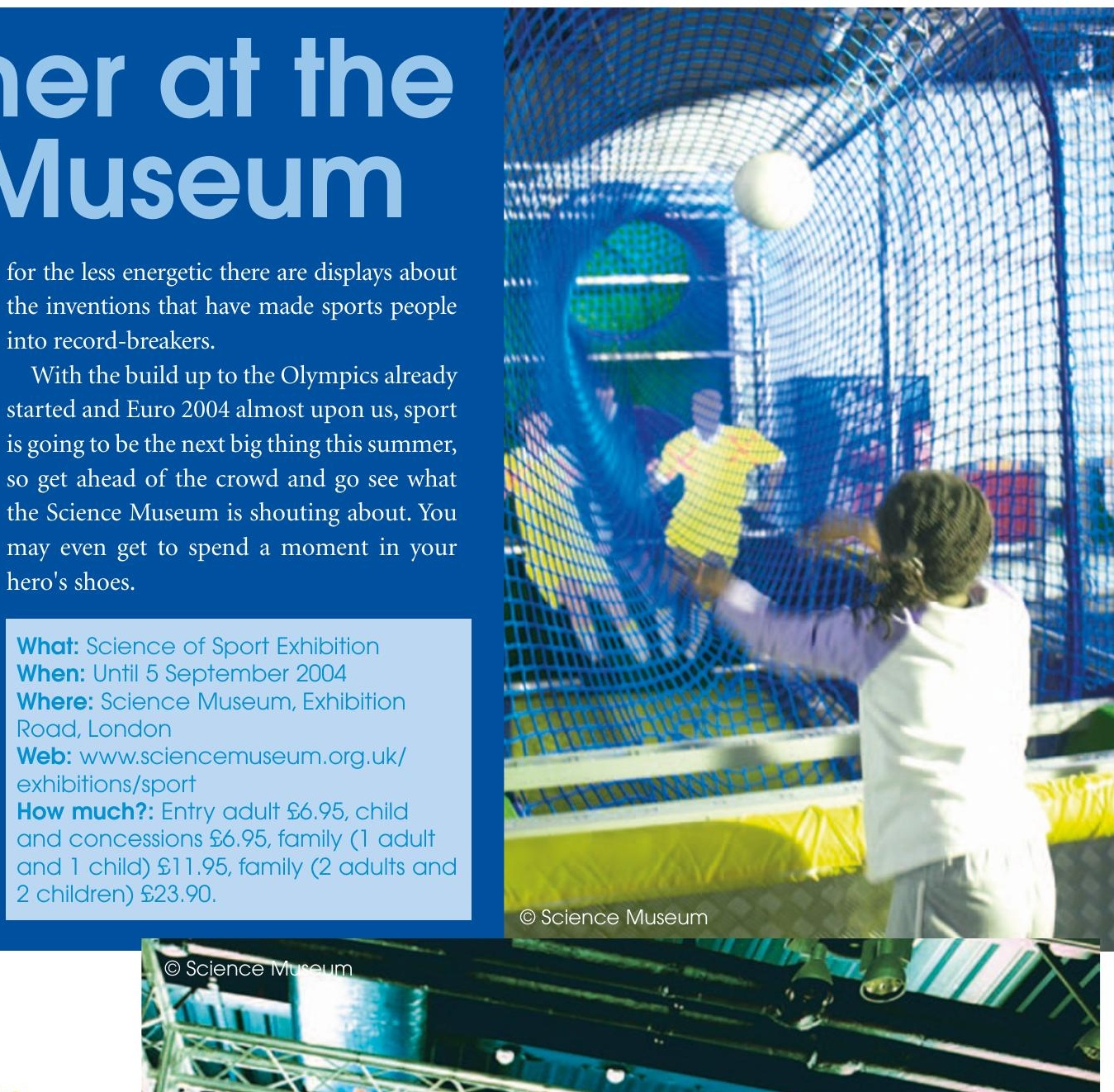
Suminer

British Dental Practice Managers' Association 2004. Conference

Date: 09.07.04-10.07.04

Venue: Highgate House Conference Centre, Northampton Website: www.bdpma.org.uk/conference

2004 Dental Nurse Study Day Programme, British Orthodontic Conference

Date: 21.09.04

Venue: Harrogate International Conference Centre Website: www.orthodontic-ong.co.uk/conference

BDHA Annual Scientific Conference \& AGM

Date: 12.11.04-13.11.04

Venue: Edinburgh International Conference Centre Website:

www.bdha.org.uk/meetings/national_meetings

GDC PCD Roadshows

Norwich City Football Club, Norwich - 15.06.04 Central Middlesex Hospital, Harlesden, London - 21.09.04 General Dental Council, central London - 20.10.04 Bart's \& Royal London Hospital, central London - 24.11.04

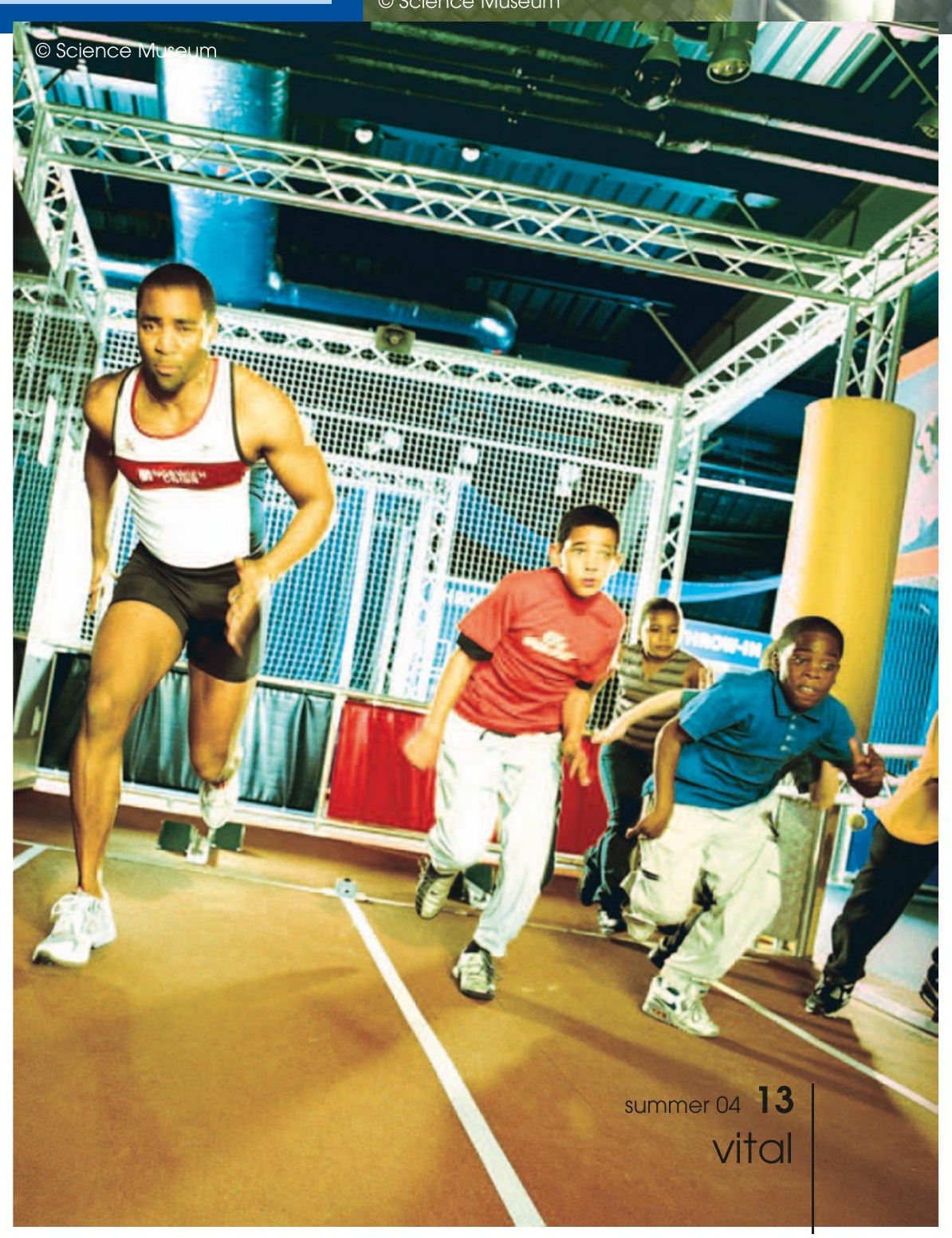

